\title{
Coupling urban event-based and catchment continuous modelling for combined sewer overflow river impact assessment
}

\author{
I. Andrés-Doménech, J. C. Múnera, F. Francés, and J. B. Marco \\ Instituto de Ingeniería del Agua y Medio Ambiente, Universidad Politécnica de Valencia, Camino de Vera s/n, \\ 46022, Valencia, Spain
}

Received: 26 May 2010 - Published in Hydrol. Earth Syst. Sci. Discuss.: 31 May 2010

Revised: 8 September 2010 - Accepted: 12 October 2010 - Published: 26 October 2010

\begin{abstract}
Since Water Framework Directive (WFD) was passed in year 2000, the conservation of water bodies in the EU must be understood in a completely different way. Regarding to combined sewer overflows (CSOs) from urban drainage networks, the WFD implies that we cannot accept CSOs because of their intrinsic features, but they must be assessed for their impact on the receiving water bodies in agreement with specific environmental aims. Consequently, both, urban system and the receiving water body must be jointly analysed to evaluate the environmental impact generated on the latter. In this context, a coupled scheme is presented in this paper to assess the CSOs impact on a river system in Torrelavega (Spain). First, a urban model is developed to statistically characterise the CSOs frequency, volume and duration. The main feature of this first model is the fact of being event-based: the system is modelled with some built synthetic storms which cover adequately the probability range of the main rainfall descriptors, i.e., rainfall event volume and peak intensity. Thus, CSOs are characterised in terms of their occurrence probability. Secondly, a continuous and distributed basin model is built to assess river response at different points in the river network. This model was calibrated initially on a daily scale and downscaled later to hourly scale. The main objective of this second element of the scheme is to provide the most likely state of the receiving river when a CSO occurs. By combining results of both models, CSO and river flows are homogeneously characterised from a statistical point of view. Finally, results from both models were coupled to estimate the final concentration of some analysed pollutants (biochemical oxygen demand, BOD, and total ammonium, $\mathrm{NH}_{4}^{+}$), within the river just after the spills.
\end{abstract}

Correspondence to:

I. Andrés-Doménech

(igando@hma.upv.es)

\section{Introduction}

Control of waste and storm water generated from urban areas has been an issue since the times of the earliest civilizations. Urban systems as we know today appeared in the early XX century. The aim of these sewage networks is to send the largest amount of effluent for treatment in order to protect population against diseases. During dry weather, in combined sewer systems, all waste water is treated, but when it rains and either interception sewers or waste water treatment plant (WWTP) capacities are exceeded, such excess is usually spilled into the receiving water body, generating combined sewer overflows (CSOs). At first it was thought that if these overflows complied with certain dilution restrictions, they would be perfectly acceptable for the receiving water body. However, about 1960, effluents produced by urban runoff were shown to be one of the main causes of water quality degradation in the receiving water bodies, especially surface continental water bodies, as they are less able to purify themselves. Thereafter the problem was studied and methods proposed to control and treat CSOs, as well as to introduce environmental criteria for design of urban drainage and sewage collection systems.

The European Council and Parliament introduced in year 2000 the Water Framework Directive (WFD), passing EC Directive 2000/60/CE, establishing a framework for political action with regard to water quality management in $\mathrm{Eu}-$ rope. This directive establishes a radical change in the way to understand water in the environment and how to protect it. WFD sets that environmental objective is to ensure spoiled water masses regain good ecological and chemical conditions. This implies that CSOs cannot be accepted because of their intrinsic characteristics, but must be evaluated for their impact on the receiving water bodies in agreement with the fixed specific aims. The impact of an overflow or spill

Published by Copernicus Publications on behalf of the European Geosciences Union. 
is quantified by comparing it to the so-called biological or chemical reference conditions for the water body into which it is spilled.

In the last decades, continuous and rapid growth of urban areas and the above mentioned legal requirements have favoured new alternative approaches to storm water management. These measures are generally called best management practices (BMP), sustainable urban drainage systems (SUDS) or low impact developments (LID) (Freni et al., 2010a). They encompass a wide range of solutions (infiltration, storage, ...) which enables planning, design and management of storm water to be tackled equally from hydrological, environmental and public amenity perspectives (Deutsch et al., 2003). Storm tanks are certainly one of the most widely used control measures against combined sewer overflows. As far as impact reduction on the receiving water body is concerned, a storm tank acts fundamentally in two ways: on one hand, it avoids large quantities of water arriving at the waste water treatment plant during a storm, by regulating it and avoiding a massive overspill into the reception water body, if it overflows or if the downstream collection system does. On the other hand, keeping the water within the tank helps sedimentation and subsequent elimination of associated pollutants. With a correct tank volume, quite good levels of efficiency can be achieved in terms of frequency, maximum concentration or spills duration, objectives generally not guaranteed with anti-CSO measures such as floodgates or spillways (Calabro and Viviani, 2006).

For many years, variables such as frequency or total spill volume have been accepted as reasonable indicators to evaluate the impact of pollution in receiving water bodies. Being aware of their limitations, the frequency and/or spills volume can themselves be a good tool for evaluating the system efficiency (Lau et al., 2002), given that in general terms, the more frequent the spills, the lower the impact on the receiving water bodies. Nevertheless, coming back to the Framework Directive, it becomes imperative to characterise the alteration generated by a CSO on the receiving water bodies, i.e., to consider the interaction produced between both elements. Thus, some authors have shown that frequency or spills volume analysis are not fully adequate for describing the impact on the receiving water body according to the WFD requirements (Engelhard et al., 2008; Freni et al., 2010b).

In urban drainage analysis, integrated approaches aim to study quantitative and qualitative aspects of two or more system components together: the sewage network, the WWTP and the receiving water bodies (Rauch et al., 2002; Freni et al., 2009).

This study follows an approach of this type, analysing separately the system components and then coupling the results together. The first component is made up of simulation of a drainage network of various urban areas; the second corresponds to hydrological modelling of the river basin, which receives the CSOs from these areas. Lastly, the impact of urban overflows on river water quality has been estimated by coupling the two sets of results by mean of a simple mixing model and adopting event mean concentrations for CSO pollutants (as justified in Sect. 5.2).

An important initial question is to decide whether the problem should be approached through continuous simulation or event-based analysis. Continuous simulation has been used widely to evaluate the performance of storm tanks with different storage volumes, devices and operational rules (Calabro and Viviani, 2006). In fact, if continuous simulation is used, all the conditioning factors over the final response of the storage tank and its long-term efficiency can be taken into account. This strategy, however, can be impractical for sizing the system or establishing a proposal for actions with some alternatives, where more general and simpler methodologies could be more appropriate. Methods based on design rules have the advantage of being simple and allow to quickly screen a wide range of design alternatives. Conversely, simulation procedures are more time consuming but mainly, they can be used to refine the final solution by exploring a few number of selected alternatives. Of course, the cost of simplification comes down to a loss in representation of certain factors within the process. In this sense, drainage systems with detention tanks (so called interception-detention systems) analysis with an event-based simulation approach, has shown certain important restrictions especially in case of detention tanks (Calabro, 2004). In fact, it is really difficult to reproduce a single input due to the complex nature of external variables of rainfall process. The methodology presented in this paper, however, demonstrates the great usefulness and potential for diagnosis and characterisation of system efficiencies by combining interception (sewers) and detention (tanks) to reduce spills magnitude and frequency from sewage systems into the receiving water body.

Also, the objective of river basin hydrological modelling is to generate temporal series of streamflows in urban areas for the lower river basin to consider the CSOs impacts on the river, with special relevance in summertime when streamflow is dramatically reduced. In this component of the coupled model strategy, spatial-temporal variability of streamflow is investigated at various simulation points along the lower river system near to the region's larger settlements and industrially developed areas. In this work, CSO effects into the river will be studied at these locations, to find out the present situation and its influence on river water quality. In this case, continuous simulation of the rainfall-runoff process is an essential tool to be able to estimate the initial moisture state and base flow prior to any storm event causing the streamflow to rise. For this reason, hydrologic model is calibrated on a daily scale, which is the temporal resolution of most of the available hydrometeorological information to be downscaled later to an hourly model. Input data for the hourly model include three rainfall time-series, synthetically reconstructed from previous studies. Besides, some changes in calibration strategy were introduced to take into account the lack of hourly streamflow data. Finally, river basin and urban 


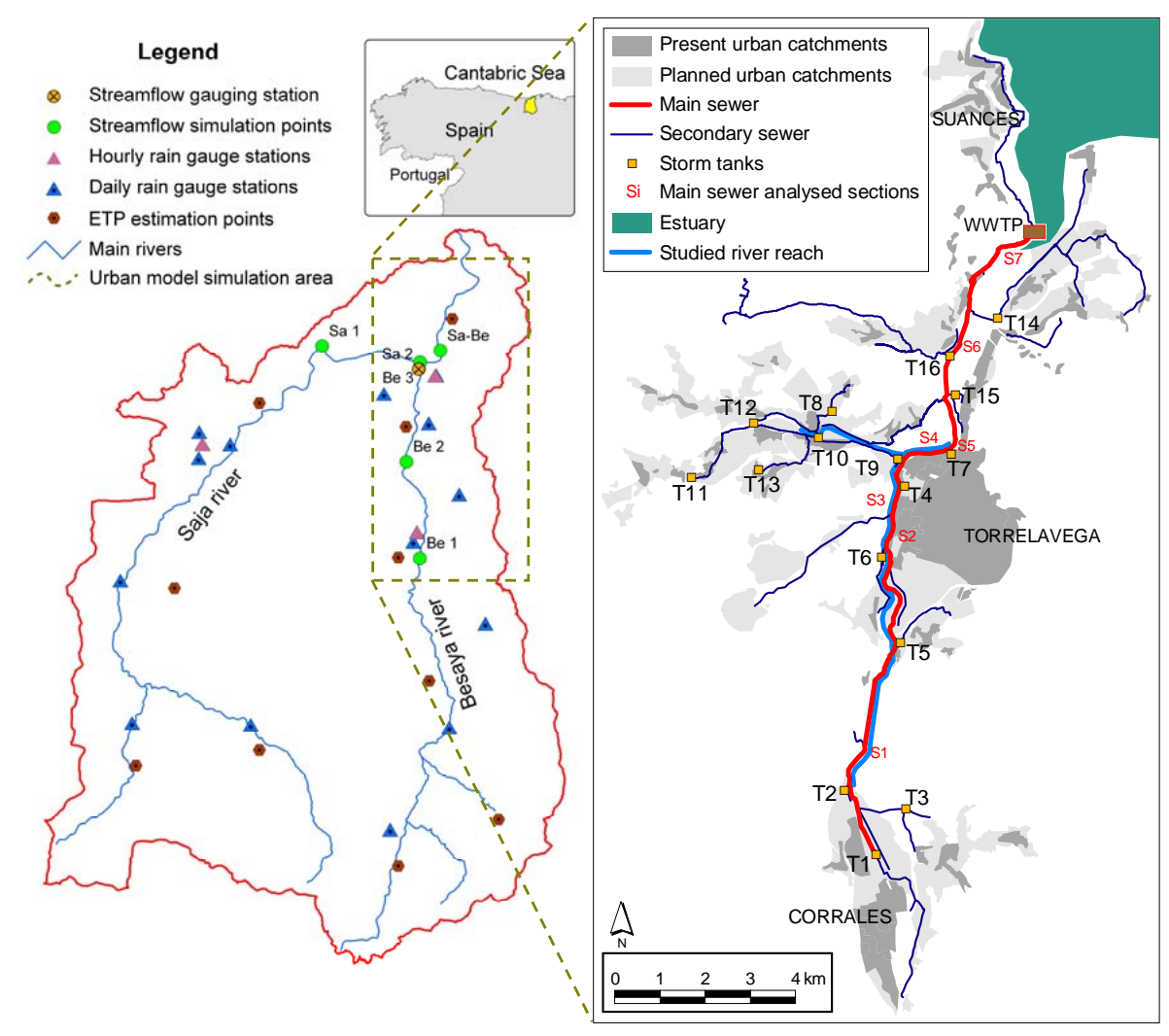

Fig. 1. Left: River basin, main drainage network, rain-gauges, gauging point, PET estimation points and fluvial simulation points. Right: Present urban catchment and future planning, main and secondary sewers, storm tanks and main sewer sections location, and WWTP.

models are coupled to establish the existing relationship between overflows, produced in drainage systems during storm events, and their impact on the receiving river.

\section{Case study}

The problem analysed herein is the assessment of impacts produced by CSOs from urban sewer network in the neighbourhoods of Torrelavega city (located in the Northern coast of Spain), on the Saja and Besaya rivers. The study is focused upstream from the estuary, which is out of the paper scope. This involves first an analysis of the present drainage scheme, sewers and storm tanks, which collects both waste and storm water from the urban system along these two rivers; secondly, their relationship with the water transport needs to the WWTP (also not included in this analysis); and finally, the overflow reduction efficiency (reduction of the average number of spills into the receiving river) is analysed through the urban drainage model. On the other hand, it is necessary to determine the temporal evolution of streamflow in several points of the Saja-Besaya receiving river system, when spills from urban trunk sewer system are produced.

\subsection{The urban drainage network}

The Saja-Besaya basin is shown in Fig. 1 (left). The sewer system (Fig. 1, right) is composed of a main trunk sewer to which are directly drained, or through a secondary sewer, sewage networks coming from nine neighbouring municipalities.

Urban drainage system consists of a main trunk sewer which is $11 \mathrm{~km}$ long and follows the Besaya river from Corrales to its junction with the Saja River at Torrelavega and finally until the WWTP, next to the estuary, at Cueto. A total of 23 secondary sewers run into the main one. At the junctions with the main sewer, a number of storm tanks for pollutant control and peak reduction are located spilling to the river when their capacities are exceeded (Fig. 2).

At present, the system covers an area of 1430 ha, with an average runoff coefficient of 0.65 . Population covered by this system is close to 100000 inhabitants. The urban area is forecast to grow to 3610 ha. Consequently, planned increase is considerable, 2200 ha, representing a $160 \%$ growth in urban area and thus in the impervious surface.

The network has a total of 25 tanks adding up to $5530 \mathrm{~m}^{3}$ which imply a net design ratio of $6 \mathrm{~m}^{3} / \mathrm{ha}$. This value, as compared with data described in other studies seems low. 


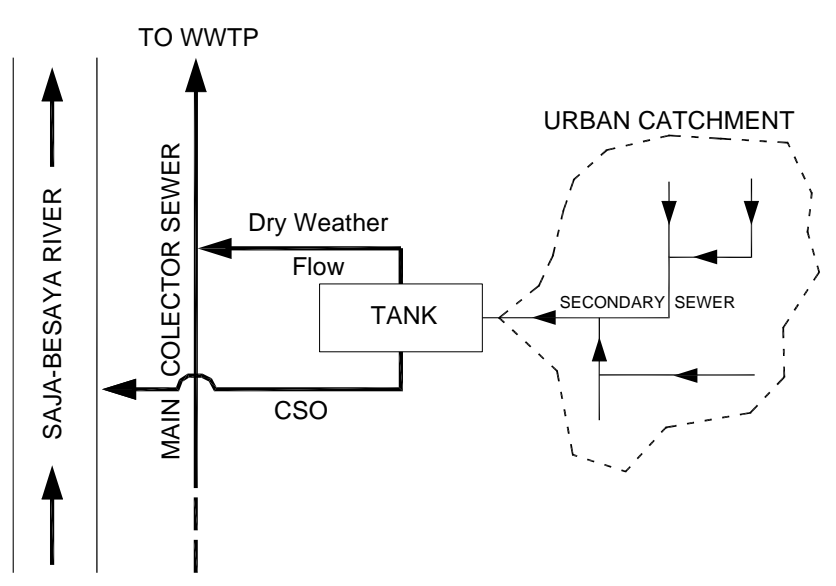

Fig. 2. Conceptual scheme of the modelled urban drainage system.

However, system diagnosis presented in this paper shows that with the adopted design criteria, acceptable reductions in CSO can be achieved. The large number of factors involved in generation of CSO and the high variability of the rainfall regime enable to find design ratios as high as $200 \mathrm{~m}^{3} / \mathrm{ha}$ (Bachoc et al., 1993) and even $300 \mathrm{~m}^{3} / \mathrm{ha}$ (Hvitved-Jacobsen et al., 1987). The range in Spain is also wide, with published recommended ratios of up to $120 \mathrm{~m}^{3} / \mathrm{ha}$ (Temprano et al., 2002).

\subsection{Saja and Besaya river basin}

The Saja and Besaya river basin is located in Northern Spain forming part of the Atlantic drainage basin. Contributing area is $1050 \mathrm{~km}^{2}$ to its mouth into the Bay of Biscay. At the rivers junction, near Torrelavega city, are located most of urban areas producing CSOs that cause problems in the receiving rivers. Average temperatures in the nearby city of Santander range between $9{ }^{\circ} \mathrm{C}$ in February and $20^{\circ} \mathrm{C}$ in August while the average annual rainfall is over $1100 \mathrm{~mm} / \mathrm{yr}$ with an average of 165 rainy days per year. In general terms, the main drainage network runs straight to the Bay of Biscay coast $(\mathrm{S}-\mathrm{N})$. Their fluvial geomorphology is characterised by straight embedded channels with steep slopes in the upper and middle basin, reaching an elevation difference close to $2000 \mathrm{~m}$ over a length of only some $50 \mathrm{~km}$.

The river basin is seated on Mesozoic geological formations, in which the limestone rocks at the Jurassic and Cretaceous levels predominate and whose main lithological units are clays and limonites, conglomerates, sandstones, limestones and marls. Deep levels are quite impervious, giving rise to underdeveloped aquifers. According to the FAO classification, main soils in the basin belong to the Cambisol group of Distric, Eutric and Humic types. The hydraulic characteristics associated with these soils were estimated indirectly using pedotransfer functions (Saxton, 1993), from a previous reclassification of soil categories defined by the Soil Conservation Service (in A, B, C and D types).
Land cover at the headwaters and on much of the basin is forest type, characterised by oaks and other hardwood species as eucalyptus and conifers. Scrubland and grazing land are predominant in the middle and lower basin and some crops are more commons in the valleys. The woodland and scrubland species have been reclassified as homogeneously behaved vegetation categories, with regard to their physiological activity, differentiating between deciduous foliage, evergreen and the intermediate type.

This classification allows to establish criteria in order to represent the variability of actual evapotranspiration (ET) rates in the annual cycle for each defined vegetation category.

Erosive processes are not very intensive at the headwaters due to forest cover, so the streamflow in these areas is clear water with high concentrations of dissolved oxygen. However, in the lower reaches, where there is a greater urban density with almost $80 \%$ of the population concentrated, along with the main industrial activities, rivers flow more slowly across the alluvial planes, water temperature is higher and so environmental aquatic conditions concerning dissolved oxygen are much worse.

\section{Urban event-based modelling}

Urban scale modelling aim is to statistically characterise CSOs to the receiving water body: flow spilled, volume and duration. The methodology is based on event simulations taken from a model of synthetic hyetographs which cover the range of probability of the two main variables in the problem: the event volume and maximum event intensity. The first variable is actually directly related to the resulting CSO volume and the second one to the maximum flow and overflow that can reach downstream sewers and, therefore, indirectly affect the former.

As shown previously, the analysis of these systems through event-based simulations suffers from certain restrictions (Calabro, 2004) as it is difficult to represent all the variables implicit in rainfall. However, event-based simulations are chosen rather than continuous simulation for two reasons: firstly, in areas with a humid climate and such continuous and persistent rainfall, the wash-off pattern is quite constant, so the effect of the variable which describes the interevent time (dry weather), is here of little relevance, if compared against Mediterranean torrential rainfall regime were interevent times are quite larger and so the pollutant buildup period heavier. It would not be the case, for example, in a semi-arid climate with longer inter-event times between rainfall episodes. Also, as far as making a diagnosis of the system and a proposal for alternatives and analysis of future scenarios is concerned, event-based simulation is more operational than continuous one. 


\subsection{Rainfall event series characterization}

An essential difference between urban model and basin model is the temporal discretisation of rainfall inputs. In fact, time resolution of rainfall inputs could be an important issue with regard to urban drainage quantity and quality modelling (Freni et al., 2010c). Hourly scale used in the basin model is not appropriate for the urban one for two main reasons: firstly, response times for the urban basin are much faster (about an hour, even minutes) than those of the river basin. But in contrast, and even more important, the use of large temporal discretisations in the urban model distorts the peak intensity variable of rainfall inputs, underestimating sewer maximum expected flows. That is why, as explained below, precipitation inputs relating to the urban model require a more precise time step definition.

Performed analysis requires high resolution data from rain gauge stations and a relatively large series, in order to correctly characterise time lag between events (interevent time), event volume $v$, its duration $b$ and, finally, the peak intensity $i_{\mathrm{M}}$. Among rainfall gauges provided by the Spanish Meteorological Agency (AEMET), the high resolution 41 year series (1942-1983) from Santander rain gauge, with 5-min time step intensity data, is suitable to proceed with the characterisation and fitting of the process variables probability density functions (pdf). The four main steps of rainfall event pattern analysis are: (1) data validation, (2) identification of statistically independent data, (3) analysis of temporal dependence and dependence between variables and finally, (4) fitting of probability density functions to the selected variables (Andrés-Doménech and Marco, 2008).

Before taking on the statistical analysis, original series of rain gauge records must be separated in statistically independent events (Restrepo-Posada and Eagleson, 1982; Adams et al., 1986; Bonta and Rao, 1988). The approach consists of selecting a critical value for the interevent time so that events separated by a dry period greater than this critical value are considered to be independent. Thus, the critical interevent time is identified so that the hypothesis that greater values than this critical one can be considered outcomes from an exponentially distributed stochastic process cannot be rejected (Andrés-Doménech et al., 2010). Results obtained in Santander for the summer period show a critical interevent separation time of $14 \mathrm{~h}$, so that, two rain pulses separated more than this value belong automatically to different precipitation events. So, for the summer period, (June to September), over the 41 records analysed there were 1121 events, giving an average of $\theta=27.3$ events per summer. Next, temporal correlation analysis proves independence of events from each other. Correlation between the four variables is also not very significant. For these reasons, independence between variables is accepted (Andrés-Doménech and Marco, 2008; Andrés-Doménech et al., 2010).

After identification of independent storms in the continuous series, the probability density functions fitting of inter-event time (distributed exponentially as it corresponds to a Poisson process), event volume $v$, duration $b$ and peak intensity $i_{\mathrm{M}}$ is carried out. Local studies in Valencia (Mediterranean coast) and Santander (North Atlantic coast) show that exponential models, widely reported since the problem was first tackled (DiToro and Small, 1979) up to the most recent references (Adams and Papa, 2000) are not at all satisfactory for $v, b$ and $i_{\mathrm{M}}$, so other alternatives should be found (Balistrocchi et al., 2008). High probability density observed close to the origin of nearly all these cases leads to postulate some other candidate pdfs, as Weibull, Gamma-2, Lognormal or Pareto. For climate characteristics in areas such as Santander, Pareto distribution reproduces very closely the characteristics of the studied variables (Andrés-Doménech and Marco, 2008; Andrés-Doménech et al., 2010).

\subsection{Synthetic rainfall events}

Main problems to be diagnosed in the system are sewer flow capacities and their surcharge and, especially, CSOs from storm tanks into the river. Main rainfall descriptors involved in these concerns are maximum event intensity and rainfall volume. The former is in fact directly related to the sewer flow conveyance and possible surcharge states. The latter is also a decisive variable for the CSO analysis. Consequently, synthetic hyetographs defined later combine different levels of non-exceedance probability of these two variables.

Once the duration of the hyetographs has been fixed to $12 \mathrm{~h}$ (i.e., the 0.50 percentile), combinations of three maximum intensities and nine event volumes are established, in order to pay special attention to the characterisation of spill frequency into the river: 27 synthetic hyetographs, result from this method. Intensity discrete values considered correspond to the $25 \%, 50 \%$ and $75 \%$ percentiles and in the case of volumes, $10 \%, 20 \%, \ldots, 80 \%$ and $90 \%$ percentiles are used.

Synthetic storms are defined through the following hyetograph expression

$i(t)=\left\{\begin{array}{cc}C_{1} t^{\mathrm{N}} & 0 \leq t \leq k b \\ C_{2}(t-b)^{\mathrm{N}} & k b \leq t \leq b\end{array}\right.$

where $i(t)$ is intensity at time $t, b$ is the event duration and $k$ is a peak position parameter $(0 \leq k \leq 1)$. Parameters $C_{1}, C_{2}$ and $N$ are determined assuming event volume and maximum intensity correspond to a bivaried non-exceedance probability, as deducted from the marginal distribution functions previously adjusted (Andrés-Doménech and Marco, 2008). So each synthetic storm has an associated non-exceedance probability

$P_{\text {event }}=p\left(V \leq v, I_{\mathrm{M}} \leq i_{\mathrm{M}}\right)=F_{\mathrm{V}}(v) \times F_{\mathrm{I}_{\mathrm{M}}}\left(i_{\mathrm{M}}\right)$

Parameters $C_{1}$ and $C_{2}$ are calculated from the highest intensity instant $t=k b$ :

$C_{1}=i_{\mathrm{M}}(k b)^{-\mathrm{N}}$
$C_{2}=i_{\mathrm{M}}[(k-1) b]^{-\mathrm{N}}$ 
The event volume is calculated as

$v=\int_{t=0}^{k b} C_{1} t^{\mathrm{N}} d t+\int_{t=k b}^{b} C_{2}(t-b)^{\mathrm{N}} d t$,

so the exponent value results being

$N=\frac{i_{\mathrm{M}} b}{v}-1$.

Depending on the actual values of parameters $C_{1}, C_{2}$ and $N$, the shape of the hyetograph will correspond to a long rainfall period with quite regular intensity $(N<1)$ or to a short shower with a heavy peak intensity $(N>1)$. Notice that if $N=1$ the hyetograph is triangular (Fig. 3).

Position of the peak intensity in the synthetic events is fixed by the parameter $k$. To simplify the analysis, the mean representative value from historic series $(k=0.4)$ is adopted. Calabro (2004) deducts that the position of the peak intensity is not the most important factor in evaluating the corresponding CSO impact. He concludes, however, that during long rainfall events, a late peak accentuates generated volumes and maximum flows, while for short events, an early peak favours pollutant wash-off to the receiving water body.

The reason for simulating the system with this model of synthetic events lies on the advantage of making a simultaneous diagnosis of conveyance (sewers) and storage (tanks) capacities. Also it will be possible to deduct the system failures frequency law (sewer surcharges and overflows to the receiving water bodies). These synthetic events are, thus, the inputs of the urban model.

\subsection{Urban drainage model}

The urban drainage model is built using Infoworks CS (Wallingford Software). Infoworks is a hydrologic and hydraulic modelling tool which simulates the whole watercycle in urban areas. The planning focus of the study and the fact that parameters used and calibrated in previous works have been respected, allow using a simple runoff production model based on runoff coefficients. Values of 0.90 for densely populated and very impervious areas, 0.70 for industrial areas with some green spaces and 0.40 for sparsely populated and more pervious areas are used. Surface runoff has been modelled with simple non-linear reservoirs, whose discharge coefficients are directly related to the basin morphological parameters and land uses. Lastly, routing in the drainage network is solved with the complete Saint-Venant equations and the Preissmann's finite differences scheme.

The model was run for the 27 rainfall events defined above. Each simulation lasted $36 \mathrm{~h}$, (three times the maximum duration of precipitation inputs). The maximum calculation time step was $15 \mathrm{~s}$ and results were stored each minute (rainfall inputs were time stepped with 1-min resolution from the continuous expression, Eq. 1, to be used as input of hydraulic model). To consider spills into the receiving water body from storm tanks, a threshold was established. It was considered

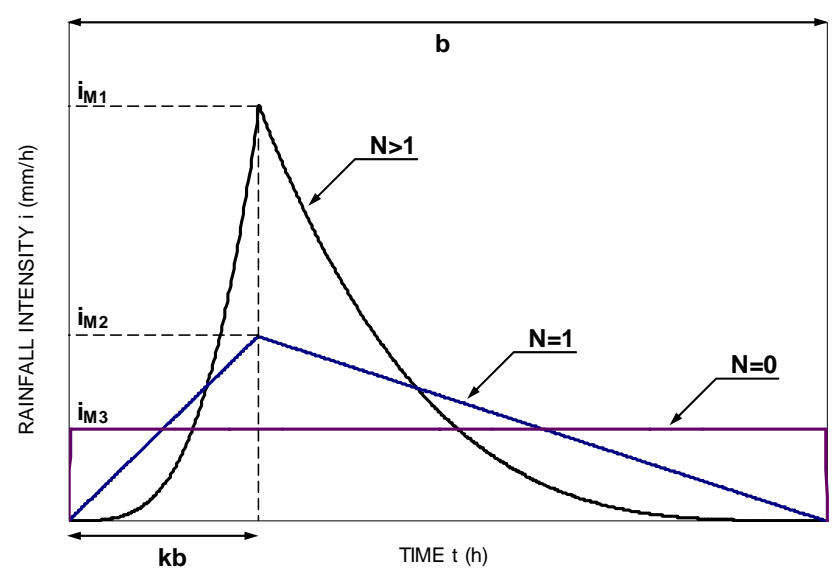

Fig. 3. Synthetic storm shape depending on N-parameter.

to be a spill if flow to the river exceeded $10^{-4} \mathrm{~m}^{3} / \mathrm{s}$. An absolute 0 -value cannot be considered here because instabilities for very low flow values could distort results. Given the order of magnitude of base flow in the receiving water body (see next section), a $10^{-4} \mathrm{~m}^{3} / \mathrm{s}$ CSO peak flow is considered to be small enough not to produce a relevant impact on it.

Results corresponding to spills are extracted from the 27 simulations (whether or not a spill occurs and, if it does, its volume and duration) and so related to flow volumes and system surcharges in sewers with the aim of diagnose the system.

\subsection{Interception sewer diagnosis results}

Each of the 27 defined events has an associated probability density in the bivaried space $\left(v, i_{\mathrm{M}}\right)$ equal to $p_{i} q_{j}$, being $p_{i}$ the event volume marginal probability $(i=1, \ldots, 9)$ and $q_{j}$ the event maximum intensity marginal probability $(j=1,2$, 3 ). From the results from each of these simulations, the following data to characterise the system response is obtained. Figure 4 shows maximum flow associated with the rainfall event probability level that can be expected in main sewer S1 and S7 sections. Each of the three curves corresponds to one of the three maximum intensity percentiles considered. Volume percentiles of rainfall events are represented in the abscissa axis.

From these results, the drainage system can be characterised for some representative reaches, by estimating the average number of surcharges per summer

$\theta_{\mathrm{C}}=\theta \sum_{i=1}^{9} \sum_{j=1}^{3} p_{i} q_{j} \delta_{i, j}$

with $\delta_{i, j}=1$ if the event $(i, j)$ simulation produces the sewer section surcharge and $\delta_{i, j}=0$ if not. $\theta$ is the number of events per summer previously characterised. 


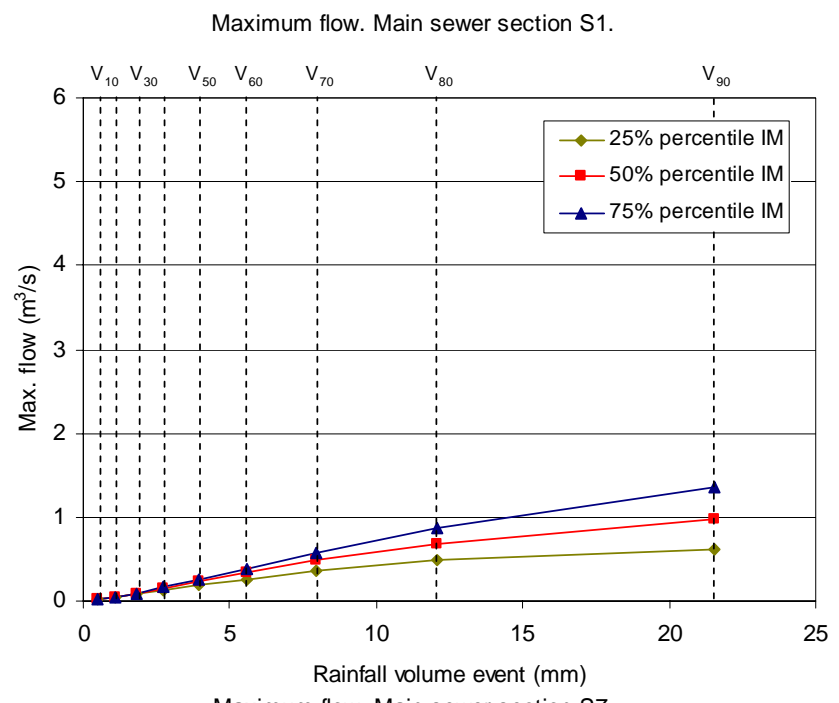

Maximum flow. Main sewer section S7.

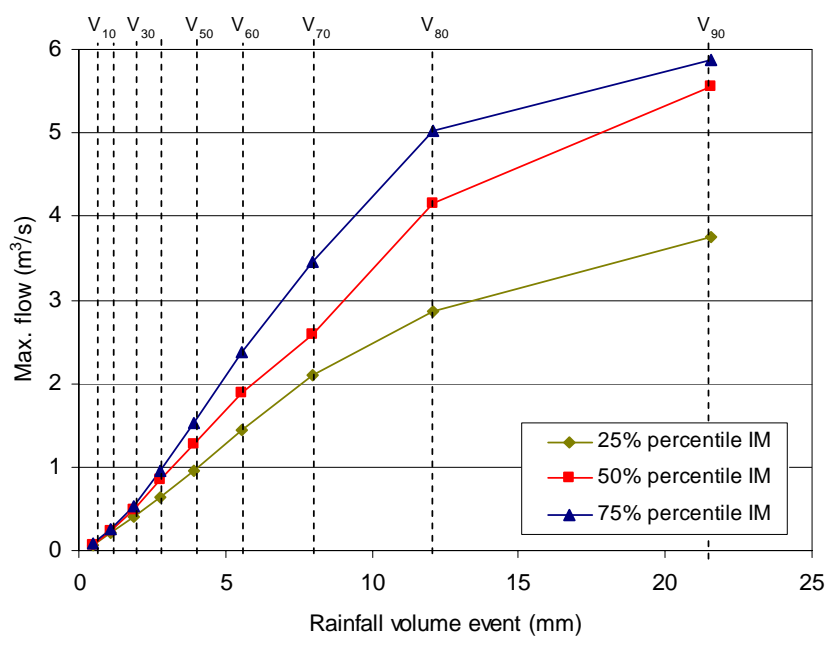

Fig. 4. Interception system diagnosis: maximum sewer flow.

On the other hand, expected value of the maximum sewer flow can be estimated as

$E\left[Q_{\mathrm{MSF}}\right]=\sum_{i=1}^{9} \sum_{j=1}^{3} p_{i} q_{j} Q_{i, j}$

where $Q_{i, j}$ is the maximum flow registered during simulation $(i, j)$, at the considered reach.

So, the surcharge characterisation of the sewer system at some key points is illustrated by the expected value of surcharges per summer and the expected value of the maximum flow in Table 1. Besides expected values of flows achieved for each sewer reach, quite moderate, the most relevant result is actually a low level of surcharges per summer. At worst sewer sections, which correspond to those located downstream in the system, 2.1 events per summer (i.e., $7.7 \%$ ) produce sewer surcharge.
Table 1. Diagnosis results for the main sewer.

\begin{tabular}{ccc}
\hline Main sewer section & $\theta_{\mathrm{C}}$ (times/summer) & $\begin{array}{c}E\left[Q_{\mathrm{MSF}}\right] \\
\left(\mathrm{m}^{3} / \mathrm{s}\right)\end{array}$ \\
\hline S1 & 0.0 & 0.31 \\
S2 & 0.4 & 0.40 \\
S3 & 0.4 & 0.41 \\
S4 & 1.3 & 0.50 \\
S5 & 2.1 & 1.61 \\
S6 & 2.1 & 1.65 \\
S7 & 2.1 & 1.76 \\
\hline
\end{tabular}

\subsection{CSO diagnosis results}

Tank performance characterisation is done in the same way. From the results of each simulation, spilled volumes are obtained for each tank, associated with the corresponding rainfall event probability level (Fig. 5).

Notice that for low volume rainfall events, maximum intensity is an important factor on the produced spill, stemming from surcharges that can happen in sewers and the effect they have on the general system response. However, for events with high rainfall volume, the maximum intensity is no longer decisive in the evolution of spill volumes (the curves tend to be parallel) and it is, clearly, directly proportional to the rainfall volume (for extreme volumes the ratio retained in the tanks is not significant as compared with the rainfall volume).

As in the previous case, the average number of spills per summer in each tank is estimated as

$\theta_{\mathrm{W}}=\theta \sum_{i=1}^{9} \sum_{j=1}^{3} p_{i} q_{j} \delta_{i, j}$.

On the other hand, expected value for the volume spilled per summer in each tank can be estimated as

$E[W]=\sum_{i=1}^{9} \sum_{j=1}^{3} p_{i} q_{j} W_{i, j}$

where $W_{i, j}$ is the volume spilled in the simulation $(i, j)$. So, the average overflow volume will be

$W_{\mathrm{m}}=E[W] \frac{\theta}{\theta_{\mathrm{W}}}$.

In a similar way, expected value of the spill duration per summer in each tank can be estimated as

$E[D]=\sum_{i=1}^{9} \sum_{j=1}^{3} p_{i} q_{j} D_{i, j}$

where $D_{i, j}$ is the duration of the spill in the simulation $(i, j)$. Therefore, the average duration of overflow per event will be

$D_{\mathrm{m}}=E[D] \frac{\theta}{\theta_{\mathrm{W}}}$. 


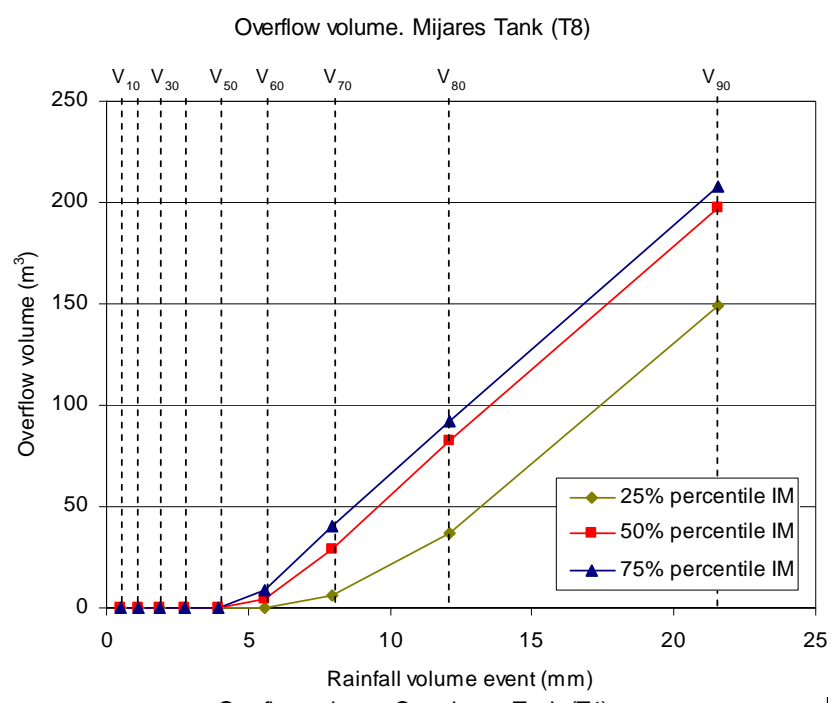

Overflow volume. Covadonga Tank (T4)

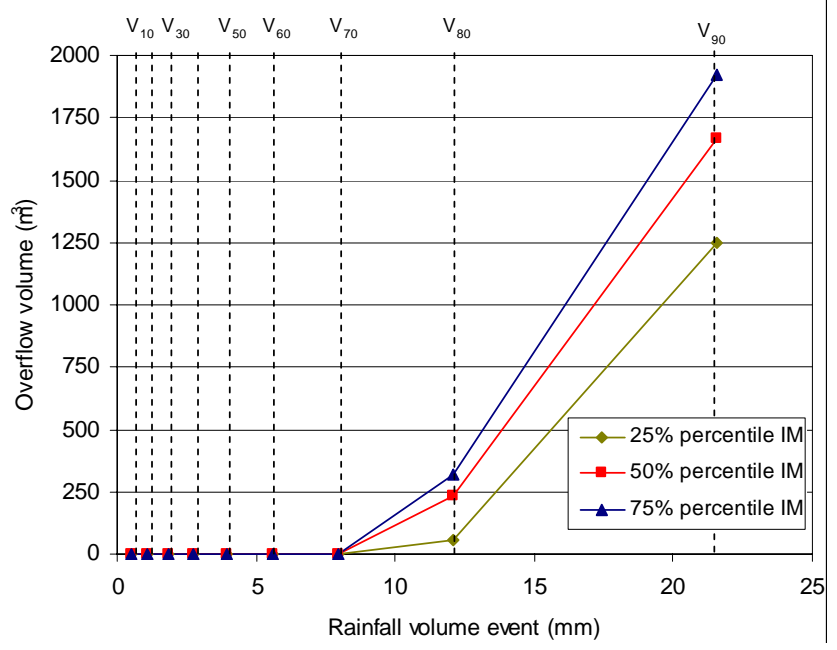

Fig. 5. Storage system diagnosis: spilled volume.

Storm tank CSO characterisation is thus quantified by obtaining, for each of them, the expected value of spills per summer and the expected spill volume and duration of the average spill (Table 2). The mean time from the beginning of the storm at which spill starts is also obtained for each tank. Note that only 6 from among 16 tanks exceed 6.8 spills per summer (75\% of summer events are so, however, detained) and only 2 exceed 11 overflows per summer (so detaining however $60 \%$ of summer events). The rest clearly detain more than $75 \%$ of summer events. These results highlight a quite good efficiency of the system for CSO detention. A special concern is also to be reported at tank T7. This tank is the greater of the whole system and provides service to the most densely populated urban area (Torrelavega). Even if it warrants the lowest number of spills per summer, note that, when it happens, CSO flow into the river is appreciable. However, for the other tanks, flows spilled into the river are quite moderate. Finally, spill start times from the beginning
Table 2. Diagnosis results of main storm tanks.

\begin{tabular}{llrrrrc}
\hline & Tank & $\begin{array}{c}\theta_{\mathrm{W}} \\
\text { (spills/summer) }\end{array}$ & $\begin{array}{r}W_{\mathrm{m}} \\
\left(\mathrm{m}^{3}\right)\end{array}$ & $\begin{array}{c}D_{\mathrm{m}} \\
(\mathrm{min})\end{array}$ & $\begin{array}{c}\text { Mean } \\
\text { CSO flow } \\
\left(\mathrm{m}^{3} / \mathrm{s}\right)\end{array}$ & $\begin{array}{c}\text { Spill start } \\
\text { time } \\
(\mathrm{h})\end{array}$ \\
\hline T1 & Corrales & 0.0 & 0 & 0 & 0 & - \\
$\mathrm{T} 2$ & Barros & 7.7 & 935 & 154 & 0.101 & 3.5 \\
$\mathrm{~T} 3$ & San Felices & 7.7 & 543 & 236 & 0.038 & 2.8 \\
$\mathrm{~T} 4$ & Covadonga & 5.1 & 683 & 205 & 0.055 & 3.1 \\
$\mathrm{~T} 5$ & Viérnoles & 1.3 & 100 & 60 & 0.028 & 4.3 \\
$\mathrm{~T} 6$ & Cartes & 4.3 & 1173 & 185 & 0.106 & 3.3 \\
$\mathrm{~T} 7$ & Sorravides & 0.4 & 8439 & 106 & 1.326 & 3.9 \\
$\mathrm{~T} 8$ & Mijares & 11.1 & 61 & 203 & 0.005 & 3.1 \\
$\mathrm{~T} 9$ & Torres & 6.0 & 442 & 300 & 0.025 & 2.3 \\
T10 & Villapresente & 11.1 & 464 & 194 & 0.040 & 3.2 \\
T11 & San Miguel & 5.1 & 912 & 257 & 0.059 & 2.6 \\
T12 & Helguera & 7.7 & 221 & 194 & 0.019 & 3.2 \\
T13 & Quijas & 8.5 & 593 & 230 & 0.043 & 2.9 \\
T14 & El Cabo & 0.0 & 0 & 0 & 0 & - \\
T15 & Barreda & 1.3 & 636 & 202 & 0.052 & 3.1 \\
T16 & Viveda & 0.0 & 0 & 0 & 0 & - \\
\hline
\end{tabular}

of the storm ranging $2-4 \mathrm{~h}$ are reported. These lags will be used later for coupling these results to river flows achieved with catchment continuous modelling.

In terms of probability, these results characterise the interception-detention system and the CSO produced into the receiving water body from urban basins. The next step is the characterisation of the river basin into which spills take place, with the aim of joining both results together to evaluate the impact these CSOs produce in the river.

\section{Catchment continuous modelling}

Evaluation of impacts generated by CSOs on the Saja and Besaya rivers requires a characterisation of streamflow pattern on an event scale basis during the whole year but especially in summer, when the flow recession period occurs. So, from the end of the spring, and during the whole summer, net rainfall is substantially less than the one registered during the rest of the year, which is characterised by a more intense rainfall regime. This strong rainfall seasonality leads to a significant reduction in the rivers base flow in summer, so sporadic storms occurring at this time of the year are responsible for greatest CSO impacts.

Streamflow is recorded daily at the $\mathrm{Be} 3$ gauge station and, to have an idea of present uncertainty, it is based on the measuring method of a scale and associated rating curve; most weather stations also take daily measurements so on this time-scale a better representation of the spatial distribution of this variable is obtained. For this reason two versions of the hydrologic model were implemented with different temporal discretisation and aims: with the first model, $\Delta t=1$ day, the objective is to obtain a good representation of flow components at the rainfall-runoff process (surface, subsurface and base flow), but especially to estimate streamflow at the 6 simulation points in summer; with the second model, 
Table 3. Calibrated values of the correction factors and $\beta$ coefficient with the automatic optimization algorithm for hourly and daily models.

\begin{tabular}{llll}
\hline Correction Factor & $\begin{array}{l}\text { TETIS parameters } \\
\text { decomposition }\end{array}$ & $\begin{array}{l}\text { Daily } \\
\text { Value }\end{array}$ & $\begin{array}{c}\text { Hourly } \\
\text { Value }\end{array}$ \\
\hline $\begin{array}{l}R_{1}-\text { Static storage capacity } \\
R_{2}-\text { Index of monthly land cover } \\
\text { density }(i=1,2, \ldots, 12) \text { for ET }\end{array}$ & $\begin{array}{l}h_{\mathrm{u}}^{*}=R_{1} \cdot h_{\mathrm{u}} \\
\lambda_{i}^{*}=R_{2} \cdot \lambda_{i}\end{array}$ & 1.428 & 1.590 \\
$R_{3}-$ Infiltration capacity & $k_{\mathrm{s}}^{*}=R_{3} \cdot k_{\mathrm{S}}$ & 1.364 & 1.470 \\
$R_{4}-$ Direct runoff hillslope velocity & $u_{\mathrm{OF}}^{*}=R_{4} \cdot u_{\mathrm{OF}}$ & 0.027 & 0.882 \\
(linear reservoir) & $k_{\mathrm{p}}^{*}=R_{5} \cdot k_{\mathrm{p}}$ & 1.0 & 1.0 \\
$R_{5}-$ Percolation capacity & $k_{\mathrm{if}}^{*}=R_{6} \cdot k_{\mathrm{s}}$ & 0.0029 & 0.0041 \\
$R_{6}-$ Subsurface flow rate (linear & & 120.1 & 120.1 \\
reservoir) & $k_{\mathrm{pp}}^{*}=R_{7} \cdot k_{\mathrm{p}}$ & 0.0 & 0.0 \\
$R_{7}-$ Groundwater loss capacity & $k_{\mathrm{bf}}^{*}=R_{8} \cdot k_{\mathrm{p}}$ & 8.21 \\
$R_{8}-$ Base flow rate (linear reservoir) & 8.21 & 0.60 \\
$R_{9}-$ Stream flow velocity & $u_{\mathrm{CF}}^{*}=R_{9} \cdot u_{\mathrm{CF}}$ & 0.60 & $0.00142[\mathrm{~mm} /(\mathrm{m} \cdot \mathrm{h})]$ \\
$\beta$ Rainfall interpolation coefficient & $X_{i}=\sum_{j=1}^{n} w_{\mathrm{oj}}\left[X_{j}+\beta\left(z_{i}-z_{j}\right)\right]$ & $0.00431[\mathrm{~mm} /(\mathrm{m} \cdot \mathrm{d})]$ & 0 \\
\hline
\end{tabular}

$\Delta t=1 \mathrm{~h}$, all events in the period with available hourly rainfall data had been reconstructed. The different water balance components for the calibration period are controlled when the change from daily to hourly scale is made. This approximation enables us to describe the main characteristics of the simulated hydrograph for all individual storms events, such as response times, peak flows and lag times between different simulation points during floods. Simulation points of interest with model outputs (Fig. 1) are located mainly close to urban areas at lower basin reaches, where CSOs occur.

\subsection{Available hydrometeorological information}

In the Saja and Besaya basin there is only one gauging station providing reliable information for the whole recorded period, containing simultaneous rainfall data. It is placed on the Besaya River, upstream from the confluence with the Saja River in Torrelavega. This station holds hydrologic records from the hydrologic year 1970-1971 to nowadays but they have been affected by a water diversion from the neighbouring Ebro River.

The available rainfall data in the basin is found on a daily scale with precipitation records since 1948 in some stations. Data density is variable in the registration data period, with better records kept between 1970 and 1982. There are also hourly series as a result of a downscaling process in Cabezón de la Sal, Corrales and Torrelavega stations, situated in the mid to low areas of the basin (Fig. 1), over a period of 36 complete years (1948-1983).

Uncertainty sources added to the precipitation downscaling process, poor representation of spatial distribution of the hourly precipitation in the basin by the small number of hourly rain gauges and lack of hourly streamflow data make it impossible to carry out a complete and reliable calibration of all the model's parameters, which will result in greater uncertainty for the simulated hourly streamflows with regard to daily ones.

Finally, potential evapotranspiration (PET) has been calculated on a daily basis at 10 points distributed over the whole basin over the 1950-1951 to 1999-2000 period, using information from diverse sources and temporal scales.

Implementation process of the hydrologic model at daily and hourly scales, as well as the methodology used for model parameters calibration, model validation, interpretation and results are described below.

\subsection{Description of the hydrological model TETIS}

The hydrological simulation model used is TETIS, version 7.2 (Vélez, 2001; Francés et al., 2002). TETIS is a hydrological model with physically based parameters distributed in space, which allows obtaining results at any point of the basin and incorporating the spatial variability of the water cycle. Even though it is fully distributed in space, TETIS has a novel effective parameter structure, called split parameter, which allows its automatic calibration (Francés et al., 2007; Vélez et al., 2009) using the optimisation algorithm SCE-UA (Duan et al., 1992). In the split parameter structure implemented in TETIS, the relationship between the a priori estimated parameter maps and the effective maps must be considered as a correction function, or in its simplest form, by way of a correction factor $(R)$ which modifies the first ones globally (Francés and Benito, 1995; Francés et al., 2007). In this way, the spatial variability of parameters in 
the basin is captured in the initial estimation and the global corrector factor modifies the magnitude of these maps. This methodology reduces drastically the number of variables to be calibrated, to a single factor per hydrologic process represented in the model (Table 3), the initial state of the five model tanks and a coefficient $(\beta)$ to incorporate in the rainfall interpolation a linear correction to take into account its variation with altitude (Francés et al., 2007).

\subsection{A priori parameter maps}

Cell size adopted for the estimation of a priori parameter maps for TETIS implementation in the Saja-Besaya basin is $500 \mathrm{~m}$. This size is in accordance with the spatial resolution of most of the available maps with physical and environmental information. It is also of the same order of magnitude of average hillslope and it is appropriate for basin size and for the computing time required for the model automatic calibration.

The original digital elevation model, with spatial resolution of $5 \mathrm{~m}$ (DEM5) has been upscaled to $500 \mathrm{~m}$ (DEM500), maintaining the topological properties of the drainage network. From the DEM500, three additional maps are generated: flow directions, accumulated cells and slopes. The first two are used to define the topological relationship of the drainage network and the last two for river channel geomorphologic characterisation.

TETIS requires at least four additional maps to be put into the system, containing: land cover indexes; upper static storage capacity $\left(h_{\mathrm{u}}\right)$, which includes interception, depression storage and soil capillary storage in root zone; upper soil permeability map $\left(k_{\mathrm{s}}\right)$; and lastly, the substrate permeability $\left(k_{\mathrm{p}}\right)$.

\subsection{TETIS model downscaling calibration and validation}

The selected calibration period covers the hydrologic years 1979-1980 to 1981-1982, and is the same for the daily and hourly scales. This fact allows to control the different components between these two time scales. The validation period covers the years from 1970-1971 to 1978-1979. Daily streamflows have been corrected to take into account that daily precipitation measurements are taken at 08:00 a.m. and, in the calibration period, the peak flow were reduced by two events whose magnitude was not compatible with the observed rainfall.

The automatic calibration process of the model has been iterative between the daily and hourly scales, using a warmingup period of three months in both cases and checking that the state variables of the model (storage in tanks) hold stationarity condition for the adopted correction factors.

The general procedure for different iterations of the calibration process between the temporal scales mentioned above is the following:
1. Objective function used in the calibration of the daily model is the root mean square error (RMSE).

2. Initial moisture state of the warming-up period (1 July 1979) was estimated assuming an average storage value in the simulated tanks for the same day in the following three years of the calibration period. The three months warming-up period guarantees the stabilisation of initial state before the first day of calibration period (1 October 1979).

3. Direct runoff hillslope velocity correction factor on the hillslope has been fixed as one in the daily model, because at daily scale, this model is not sensible to this process.

4. The R9 correction factor, for propagation velocity in the river network, was obtained in the hourly time step model by a sensitivity analysis, assuming a concentration time of $5 \mathrm{~h}$ for the biggest flood events. The resulting value was adopted in the daily scale and the remaining correction factors and the $\beta$ coefficient were automatically calibrated.

5. Groundwater losses (groundwater flow not connected with the river) are very low, compared to recharge. So, the R7 was fixed at 0 in both models.

6. The $\beta$ spatial interpolation coefficient for precipitation was adjusted at the hourly time step model, to obtain the same total volume of precipitation than at daily scale, given that observed streamflow is daily and spatial distribution of rainfall is not very well represented as mentioned above.

7. The $\mathrm{R} 2$ correction factor for evapotranspiration for the hourly time step model has been adjusted using the same criteria as for precipitation. Thus, the same volume of ET and rainfall excess on both scales is guaranteed.

8. At the hourly time step model the same initial state conditions are assumed and corrective factors for base flow and subsurface flow were maintained as for daily scale, being automatically calibrated the corresponding factors for infiltration, percolation and static storage processes.

9. For calibration of the hourly time step model, a modification has been made to the objective function to be optimised (RMSE). In this case, average value of the function is evaluated at $24 \mathrm{~h}$ intervals to compare with daily observed value (broken down into 24 equal hourly values), in an attempt to reproduce the infra-daily variability.

In Table 3 the final correction factors values are shown for daily and hourly calibrations, after various iterations following the above described sequence. 


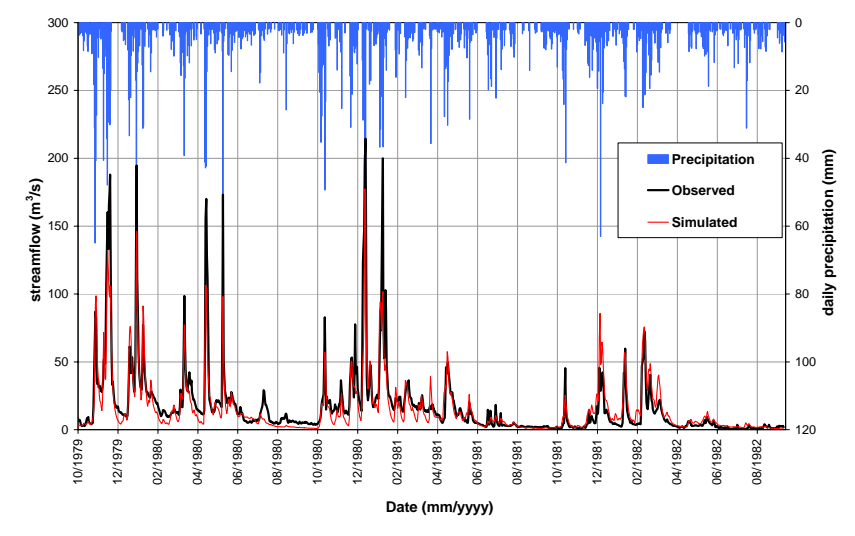

Fig. 6. Daily precipitations and streamflows observed and simulated with TETIS model at $\mathrm{Be} 3$ point during the calibration period.

Figure 6 shows the daily scale calibration, giving an efficiency index (Nash and Sutcliffe, 1970) of 0.81 and a balance error of $-4.60 \%$. For the validation period, at this time scale, the efficiency index is 0.65 and the balance error is $9.87 \%$. These results are satisfactory taking into account all sources of uncertainty in the initial information.

Considering the hourly time step model, it is not shown any statistic because streamflows are observed at daily basis. Regarding the balance, there is a tendency to slightly overestimate the baseflows. Therefore, the simulated streamflows by the daily model were adopted at the beginning of flood events and also to correct the successive simulated hourly flows.

\subsection{Hydrological modelling results in the basin}

The period from 1951-1952 (beginning of the PET series) to 1991-1992 (end of daily precipitations) has been simulated continuously on a daily scale basis. From the hydrological basin regime point of view, it can be said that there are three different periods within the annual cycle:

1. A marked summer period of very low water levels from July to September, with streamflows clearly inferior to the rest of the year. This is due to the small relative size of the aquifers, which produce a base flow representing only $12 \%$ of the total simulated streamflow at simulation point $\mathrm{Be} 3$ (similar results at other points).

2. In contrast, between November and May, streamflows are much greater due to heavier precipitations and higher moisture of the upper soil layer.

3. Finally, in June and October there is a transition between the two previously described states.

For this reason, to simulate floods during the low flow periods, only the months from July to September were taken into account.

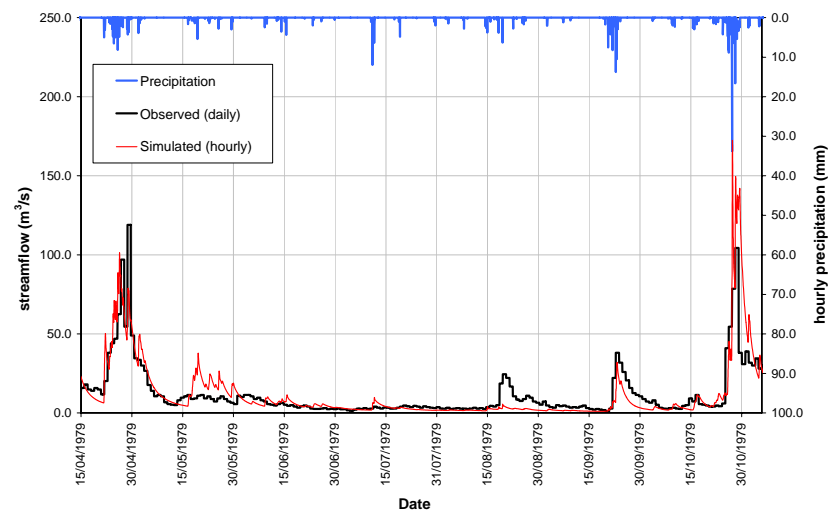

Fig. 7. Observed daily streamflows, hourly precipitation and simulated hourly streamflows at simulation point $\mathrm{Be} 3$, for part of the validation period.

The period from 1951-1952 to 1982-1983 (end of hourly precipitation data) has been continuously simulated with the hourly time step model. Figure 7 shows results obtained for several months of the validation period, including summer of 1979. Observed streamflow does not present a smooth behaviour due to daily resolution. In contrast, simulated streamflow looks continuous. Some events were not properly simulated by the hourly model due to loss of information by downscaling the areal precipitation from daily to hourly scale, since the latter rests only on 3 rain-gauges.

\subsection{Separation and characterisation of flood events}

From this continuous computed series, all flood events taking place along the summer period were selected and statistically analysed at each simulation point. To separate them, the event was considered to begin when the streamflow starts to rise, ending after 14 consecutive hours without rainfall, according to the critical interevent separation time adopted at the urban model for summer period, considering $20 \mathrm{~h}$ as the minimum flood duration At each simulation point, previous day simulated streamflow $\left(Q_{0}\right)$, hourly streamflows after 5, 10, 15 and $20 \mathrm{~h}\left(Q_{5}, Q_{10}, Q_{15}, Q_{20}\right)$ and peak flow $\left(Q_{\mathrm{p}}\right)$ were analysed. Each individual flood event $i$ magnitude was defined in terms of non-exceedance probability of the associated storm event total rainfall depth $(V)$ as

$p\left(V \leq v_{i}\right)=\frac{i}{n+1}$

Where $i$ is the ranking position of $v_{i}$ for storm rainfall depth series ranked in ascending order.

To summarize the results of all previously identified events in the simulation period, exponential functions were fitted to the empirical relations between each of the aforementioned variables and their associated storm non-exceedance probability.

Streamflow variability of $Q_{0}, Q_{5}, Q_{10}, Q_{15}$ and $Q_{20}$ is high with respect to storm probability at all simulation 

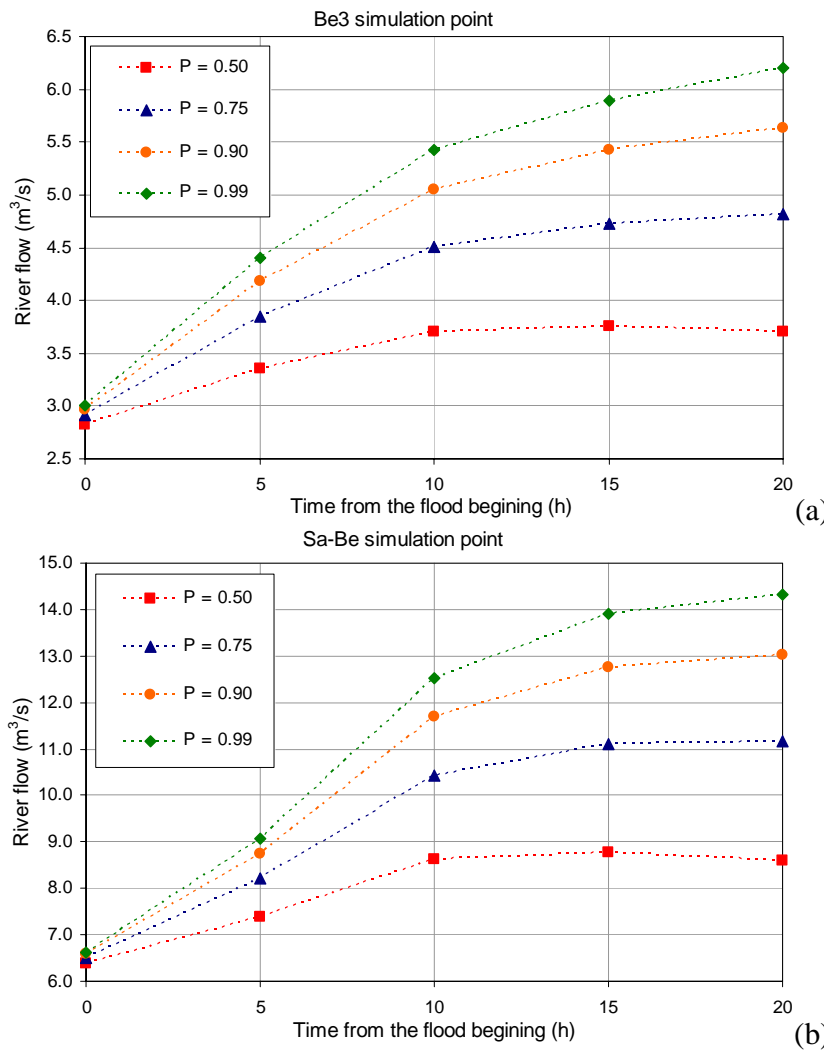

(a)

(b)

Fig. 8. Temporal evolution of streamflow for storm events during summer period. Each curve is related to a storm non-exceedance probability value. Simulation points are $\mathrm{Be} 3$ (a) and $\mathrm{Sa}-\mathrm{Be}$ (b).

points, and therefore average values were adopted. Namely, Fig. 8 shows at $\mathrm{Be} 3$ and $\mathrm{Sa}-\mathrm{Be}$ simulation points the calculated average streamflow for summer events, corresponding to non-exceedance probability levels able to generate significant CSO in the urban area ranging from 0.50 to 0.99 .

On the other hand, it can be observed that during summer period the preceding streamflow ( $t=0$ in Fig. 8) is independent of the probability level, being less than $3 \mathrm{~m}^{3} / \mathrm{s}$ at Besaya River (Be3), $3.5 \mathrm{~m}^{3} / \mathrm{s}$ for Saja River and $6.4 \mathrm{~m}^{3} / \mathrm{s}$ downstream of their junction (Sa-Be). Likewise, as storm magnitude increases, the streamflow increases as well, but not excessively. For instance, at $\mathrm{Be} 3$ simulation point for a rainstorm with an associated probability of 0.75 , the streamflow expected value is $2.91 \mathrm{~m}^{3} / \mathrm{s}$, whereas after $20 \mathrm{~h}$ from the flood beginning it increases up to $4.82 \mathrm{~m}^{3} / \mathrm{s}$ (Fig. 8).

Previous analysis was also made for the set of events corresponding to the rest of the year (October to June). In contrast to summer events, during the rest of the year there is a slight increase in the preceding streamflow with storm probability, due to greater correlation between rainstorm episodes for wet months. This highlights that the preceding average streamflows for the whole range of probabilities are approximately four times greater than those of the summer period. For example, at point $\mathrm{Be} 3$, the preceding streamflow for an
Table 4. Case study water quality objectives under current Spanish legislation.

\begin{tabular}{llll}
\hline USE & Quality required & BOD & $\mathrm{NH}_{4}^{+}$ \\
\hline Water supply & A2 & $\leq 5 \mathrm{mg} / \mathrm{l}$ & $\leq 1.5 \mathrm{mg} / \mathrm{l}$ \\
Fish life & Salmon & $\leq 3 \mathrm{mg} / \mathrm{l}$ & $\leq 1 \mathrm{mg} / \mathrm{l}$
\end{tabular}

associated storm probability of 0.50 in summer is $2.82 \mathrm{~m}^{3} / \mathrm{s}$, while for the rest of the year it increases to $11.96 \mathrm{~m}^{3} / \mathrm{s}$; at point $\mathrm{Sa} 2$, the corresponding values are 3.50 and $13.30 \mathrm{~m}^{3} / \mathrm{s}$; and downstream the rivers junction these values are 6.38 and $25.7 \mathrm{~m}^{3} / \mathrm{s}$, respectively.

These results allow to relate river streamflows with rainfall magnitude through its probability. In this way, from a probabilistic point of view, the existing streamflow conditions can be established at any point of the river network when the associated CSO occurs.

\section{Coupled results}

\subsection{Environmental objectives}

The established River Basin Management Plan sets water quality objectives for the rivers to be met. In this case, for the Saja and Besaya rivers, quality criteria are established for two uses: urban water supply and river suitability for fishlife.

CSOs impact analysis into the river has been done exclusively using two parameters: biochemical oxygen demand (BOD) and total ammonium $\left(\mathrm{NH}_{4}^{+}\right)$. Maximum admitted concentrations of these pollutants for each considered uses are imposed by both Spanish and European current legislation. European 75/440/CEE Directive for potable water and the corresponding fish-life aptitude 2006/44/CE Directive must be considered. Nevertheless, in this case, Spanish legislation has to be considered since it is more restrictive. For urban water supply, Spanish legislation (order 927/1988) classifies surface raw water for drinking in three groups (A1, A2 and A3), according to the degree of treatment it must undergo, and establishes limit values for each pollutant. Basin plan establishes that A2 quality must be reached for the Saja and Besaya rivers. As far as aptitude for fish life is concerned, it is classified as apt for salmon or apt for cyprinidae, depending on river reach sensitivity. The River Basin Management Plan demands salmon quality for both Saja and Besaya rivers. In the following table, objectives for each considered pollutants can be seen.

Table 4 shows values to be more restrictive when they correspond to fresh water fish production, so these will be the values that should not be exceeded in the river to comply simultaneously with both quality objectives. 
Table 5. Average flow volumes and starting time of the CSO for a non-exceedance probability $P=0.75$.

\begin{tabular}{llcc}
\hline $\begin{array}{c}\text { Simulation } \\
\text { point }\end{array}$ & $\begin{array}{l}\text { Storm tanks upstream with } \\
\text { more than 7 spills per summer }\end{array}$ & $\begin{array}{c}\mathrm{CSO} \text { mean flow } \\
Q_{\mathrm{U}}^{\mathrm{P}}\left(\mathrm{m}^{3} / \mathrm{s}\right)\end{array}$ & $\begin{array}{c}\text { Mean spill time } \\
\text { start (h) }\end{array}$ \\
\hline $\mathrm{Be} 1$ & $\mathrm{~T} 2, \mathrm{~T} 3$ & 0.139 & 3.2 \\
$\mathrm{Be} 3$ & $\mathrm{~T} 2, \mathrm{~T} 3$ & 0.139 & 3.2 \\
$\mathrm{Sa}$ & $\mathrm{T} 8, \mathrm{~T} 10, \mathrm{~T} 12, \mathrm{~T} 13$ & 0.107 & 3.1 \\
$\mathrm{Sa}-\mathrm{Be}$ & $\mathrm{T} 2, \mathrm{~T} 3, \mathrm{~T} 8, \mathrm{~T} 10, \mathrm{~T} 12, \mathrm{~T} 13$ & 0.265 & 3.1 \\
\hline
\end{tabular}

\subsection{Coupled scheme and results}

With the coupled simulation scheme described above, each representative synthetic event generated within the urban model could be associated with a description of the most probable state of the receiving rivers using their response times and the temporal evolution of streamflow in the river during the following $20 \mathrm{~h}$ from the beginning of the hydrograph. From Fig. 8, as explained in previous section, expected streamflow in the river at the spill point of interest for a non-exceedance level of probability $P, Q_{0}^{\mathrm{P}}$ are obtained.

In parallel, magnitude of spills from urban catchments are characterised from the probabilistic approach (Fig. 5). Volume and duration values for the same non-exceedance level $P, W_{\mathrm{U}}^{\mathrm{P}}$ and $D_{\mathrm{U}}^{\mathrm{P}}$ respectively, can hence be deducted.

In addition, as a result of sampling, values are adopted for the average concentrations of pollutants analysed in CSO and at the receiving river upstream the urban areas where spills occur. $C_{\mathrm{U}, i}$ is the average concentration of the pollutant $i$ in $\mathrm{CSO}$ and $C_{0, i}$ is the average concentration of the same pollutant within the river upstream the urban areas. The evaluation of impact is made for the BOD and total ammonia parameters. Average values during the summer period of base concentrations in the river for both pollutants are $C_{0, \mathrm{BOD}}=2.9 \mathrm{mg} / \mathrm{l}$ and $C_{0, \mathrm{NH} 4}=0.4 \mathrm{mg} / \mathrm{l}$, according to sampling data provided by the water district. Besides, concentrations of these pollutants in CSO are adopted from previous studies undertook in each urban catchment by the water district consistent with reference values from the literature (Ellis, 1989; MMA, 2002). Thus, the average BOD concentration per overflow is established at $C_{\mathrm{U}, \mathrm{BOD}}=150 \mathrm{mg} / \mathrm{l}$ and for the ammonium at $C_{\mathrm{U}, \mathrm{NH} 4}=2 \mathrm{mg} / \mathrm{l}$. These values are in the lower range of intervals usually reported by literature; nevertheless, they are appropriate to mainly sparse urban areas as those in the study.

Evaluation of the immediate impact of CSO in the receiving rivers is estimated with Eq. (14), for the non-exceedance probability level $(P)$, being $C_{\mathrm{F}, i}^{\mathrm{P}}$ the final concentration of pollutant $i$ in the river straight after the spill. This approach based on dilution criteria in a succession of steady states is here appropriate as we are dealing with a far-field quality
Table 6. Coupled results for a non-exceedance probability $P=0.75$.

\begin{tabular}{lcccc}
\hline $\begin{array}{c}\text { Simulation } \\
\text { point }\end{array}$ & $\begin{array}{c}\text { River flow } \\
Q_{0}^{\mathrm{P}}\left(\mathrm{m}^{3} / \mathrm{s}\right)\end{array}$ & $\begin{array}{c}\text { CSO mean } \\
\text { flow } Q_{\mathrm{U}}^{\mathrm{P}} \\
\left(\mathrm{m}^{3} / \mathrm{s}\right)\end{array}$ & $\begin{array}{c}\text { River BOD } \\
\text { concentration } \\
\text { after CSO } \\
Q_{\mathrm{F}, \mathrm{BOD}}^{\mathrm{P}}(\mathrm{mg} / \mathrm{l})\end{array}$ & $\begin{array}{c}\text { River } \mathrm{NH}_{4}^{+} \\
\text {concentration } \\
\text { after CSO } \\
Q_{\mathrm{F}, \mathrm{NH} 4}^{\mathrm{P}}(\mathrm{mg} / \mathrm{l})\end{array}$ \\
\hline $\mathrm{Be} 1$ & 2.81 & 0.139 & 9.82 & 0.47 \\
$\mathrm{Be} 3$ & 3.51 & 0.139 & 8.50 & 0.46 \\
$\mathrm{Sa}$ & 4.17 & 0.107 & 6.58 & 0.44 \\
$\mathrm{Sa}-\mathrm{Be}$ & 7.60 & 0.265 & 7.86 & 0.45 \\
\hline
\end{tabular}

phenomenon, where advection is dominant and dispersion negligible.

$C_{\mathrm{F}, i}^{\mathrm{P}}=\frac{C_{\mathrm{U}, i} Q_{\mathrm{U}}^{\mathrm{P}}+C_{0, i} Q_{0, i}^{\mathrm{P}}}{Q_{\mathrm{U}}^{\mathrm{P}}+Q_{0, i}^{\mathrm{P}}}=\frac{C_{\mathrm{U}, i} \frac{W_{\mathrm{U}}^{\mathrm{P}}}{D_{\mathrm{U}}^{\mathrm{P}}}+C_{0, i} Q_{0, i}^{\mathrm{P}}}{\frac{W_{\mathrm{U}}^{\mathrm{P}}}{D_{\mathrm{U}}^{\mathrm{P}}}+Q_{0, i}^{\mathrm{P}}}$

To fix the probability level $P$ for which results are evaluated, as reported before, $25 \%$ of the $\theta=27.3$ events occurring in average per summer produce significant CSO (Table 2). So, the adopted probability of non-exceedance is $P=0.75$. The values $W_{\mathrm{U}}^{\mathrm{P}}, D_{\mathrm{U}}^{\mathrm{P}}$ and $Q_{0}^{\mathrm{P}}$ correspond to a non- exceedance probability of 0.75 and are deducted from the urban drainage model and the basin one respectively. In Table 5, average flow volumes of the CSO affecting each simulation point in the river are shown, deducted from values in Table 2. It also shows the instant the overflow occurs from beginning of the storm.

Results in Table 6 shows, from the beginning of the spill, the expected streamflow in the river $Q_{0}^{\mathrm{P}}$ for each analysed point, at the moment when the CSO happens and for a nonexceedance probability of 0.75 . These values are deducted from results summarized in Fig. 8. Finally, with Eq. (14) the instantaneous BOD and $\mathrm{NH}_{4}^{+}$concentrations in the river after the spills are calculated. Table 6 shows the results obtained in four of the considered simulation points in the river system. Base river concentration for BOD of $2.9 \mathrm{mg} / \mathrm{l}$ is the threshold level for salmon-bearing rivers (Table 4). Consequences are therefore clear. When a spill from urban runoff occurs, river BOD rises to values around $10 \mathrm{mg} / \mathrm{l}$, which do not comply with the quality values required. The same effect is not seen, however, with ammonium, since spills produce increases in river concentration which are not significant (Table 6). Results obtained with regard to the BOD highlight the importance of minimising overflows from urban environments into river systems especially during low flow periods. However, notice that concentrations obtained in the river after the CSO correspond to intermittent and transitory occurrences and so must be evaluated as such. In any case, the recurrence level with which significant discharges are produced, ( 1 of each 4 events per summer) and with resulting pollution parameters in the river after they happen (Table 6) allow to conclude that 


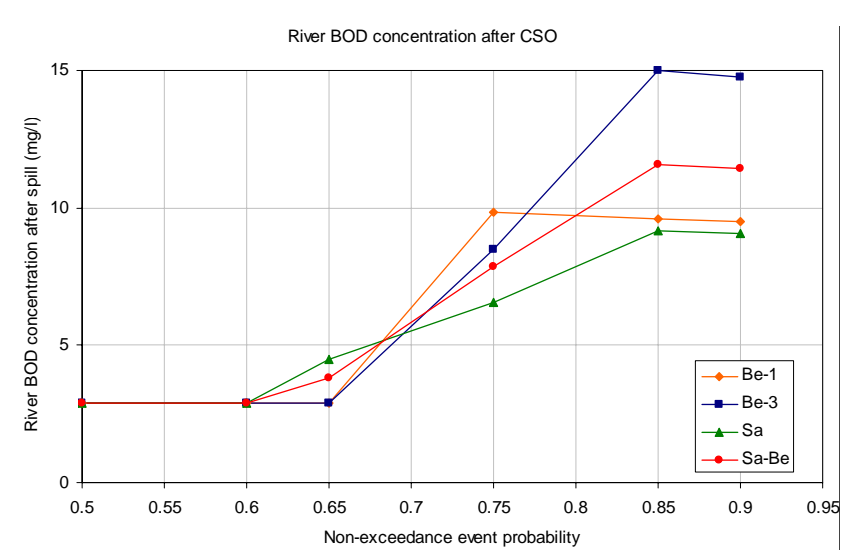

Fig. 9. BOD concentration in the river after CSO for different nonexceedance storm probabilities.

the analysed system although not strictly in agreement with legal imperatives does provide an acceptable service level.

\subsection{Sensitivity analysis}

Results obtained are analysed with two sensitivity tests. First sensitivity of results on a fixed probability level is analysed, and secondly with regard to the time lag from the beginning of the storm in the river basin and the actual overflow.

To evaluate the incidence of the event magnitude on river concentrations after spills, a sensitivity analysis of the BOD results regarding the non-exceedance probability was done, following the above described methodology and varying the threshold probability level $P$. As can be seen in Fig. 9, as the non-exceedance probability level increases the spilled flow increases too leading to higher BOD concentrations in the river after the CSO. However, for high non-exceedance probabilities, increase in volume spilled by the tanks moderates and is compensated by greater streamflow in the river which leads to a stabilisation of the river BOD after the overflow. This fact occurs for a lower probability at $\mathrm{Be} 1$ simulation point which is the one located upstream in the system, which is only affected by the spill from two tanks (T2 and T3).

Lastly, Fig. 10 shows sensitivity analysis results for BOD river concentration depending on the time lag between spill and start of the storm in the river basin, conditioning expected streamflow in the river $Q_{0}^{\mathrm{P}}$ when CSO happens.

The analysis of these latest results shows that as spill slows as compared to the flood start, the resulting BOD concentrations reduce as streamflow increases significantly in the river (Fig. 8), while, of course, river peak flow time is not exceeded.

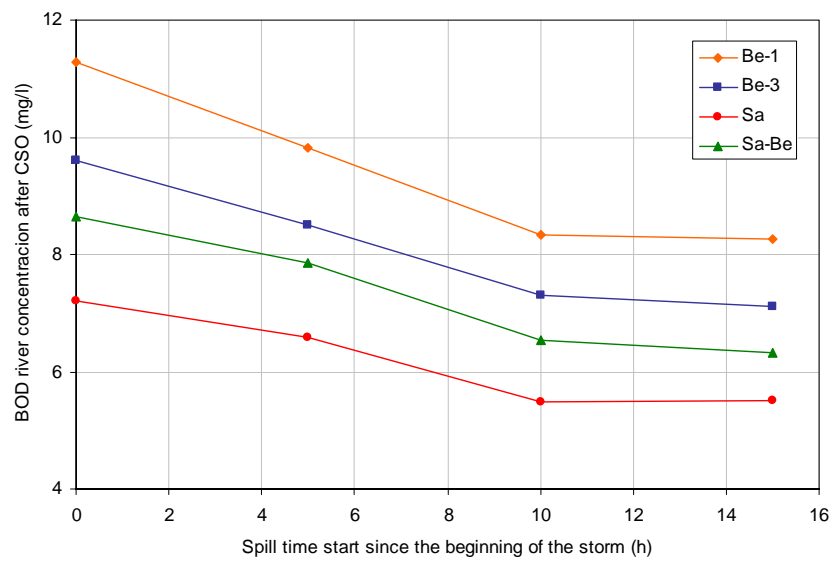

Fig. 10. BOD concentration in the river after CSO for nonexceedance storm probability $P=0.75$.

\section{Conclusions}

Indicators such as frequency or spill volume reduction seem to be good tools for assessing storm tanks behaviour for the CSO reduction into receiving water bodies. Nevertheless, according to the EU Water Framework Directive, it is at present necessary to analyse specifically the impact these CSO generate into the environment. The study presented herein follows an approach with this aim, analysing separately an urban drainage network and the river basin into which CSO occur. Finally, results from these two parallel studies are coupled to assess the CSO impact into the river. The case study developed corresponds to the urban drainage network of Torrelavega (Spain) and its neighbouring municipalities whose spill runoff overflows into the Saja and Besaya rivers.

Urban scale modelling aim is to statistically characterise CSO to the river with their spilled flows, volume and duration. Prior, a rainfall analysis is achieved in order to build synthetic storms which cover the full range of probability of the main rainfall descriptors for this issue: rainfall event volume and maximum intensity. Thus, each synthetic storm has an associated non-exceedance probability and provides input for the simulations performed with Infoworks. With those results, CSO characterisation is quantified by obtaining for each storm tank the expected value of spill frequency, volume and duration. Besides, the average instant from the beginning of the storm at which spill starts is also obtained in order to successfully accomplish temporal coupling between both models.

Evaluation of CSO impacts into the receiving water bodies requires the analysis of streamflow pattern in the river on an event scale basis. Thus, a continuous hydrological basin model is performed with TETIS to provide the event response in the basin attached to a storm non-exceedance probability. To reach this objective, two versions of the model are implemented. First, the model is calibrated at daily scale to assess good representation for all flow components. Then, 
with hourly discretisation, event analysis is achieved. Simulation points are located where $\mathrm{CSO}$ from urban areas occur. At each of them, average streamflows are obtained, associated to a non-exceedance probability level and related to the time elapsed since the storm beginning. A key feature regarding summer periods is that when events start, streamflow increases over time with higher rates during the first 10 hours and the magnitude depends strongly on the storm event probability. After $10 \mathrm{~h}$, streamflow keeps rising, though at lower rate. Another relevant feature is that as time elapses the differences between average streamflows related to the above mentioned storm probability values increase.

With this simulation scheme, each synthetic event and CSO generated with the urban model could be associated with a description of the most likely state of the receiving river, coupling both response times: river basin and urban catchment. Final evaluation of CSO impact into the river is assessed by averaging pollutant concentrations from CSO and the river base flow, and thus, estimating, final concentration within the river immediately after the overflow. The main interest of this approach is that all results, even coupled ones, are always related to the same non-exceedance probability level as a result of the coupled scheme.

Acknowledgements. This work was developed within the contract "Convenio de colaboración entre la Confederación Hidrográfica del Norte y la Universidad Politécnica de Valencia para la realización del estudio, análisis y evaluación del esquema actual de saneamiento de la cuenca baja del sistema fluvial Saja-Besaya y desarrollo conceptual de una nueva alternativa" with the Water District "Confederación Hidrográfica del Cantábrico" and partially supported by the Spanish research projects "Tetis2" (CGL200506219/HID) and "Floodmed" (CGL2008-06474-C02-02/BTE). Also, we acknowledge support from Wallingford Software by the use of their Infoworks software.

Edited by: A. Montanari

\section{References}

Adams, B. J., Fraser, H. G., Howard, C. D. D., and Hanafy, M. S.: Meteorological data analysis for drainage system design, J. Environ. Eng.-ASCE, 112(5), 824-847, 1986.

Adams, B. J. and Papa, F.: Urban stormwater management planning with analytical probabilistic method, John Wiley \& Sons, Inc, New York, USA, 358 pp., 2000.

Andrés-Doménech, I. and Marco Segura, J. B.: Multivariate rainfall distributions for stormwater detention tank sizing using probabilistic and single-event approaches, A comparison between northern and eastern Spain, Proceedings of the 11th International Conference on Urban Drainage, (CD-ROM), Edinburg, Scotland, UK, 2008.

Andrés-Doménech, I., Montanari, A., and Marco, J. B.: Stochastic rainfall analysis for storm tank performance evaluation, Hydrol. Earth Syst. Sci., 14, 1221-1232, doi:10.5194/hess-14-12212010, 2010.
Bachoc, A., Sanchez, Y., Le Guennec, B., Chebbo, G., Laplace, D., and Lin, H.: Bilan scientifique et technologique du programme de recherche sur les solides en réseaux d'assainissement, TSML'EAU, 10, 537-541, 1993.

Balistrocchi, M., Grossi, G., and Bacchi, B.: Assessment of the long term efficiency of CSO capture tanks by semiprobabilistic methods, Proceedings of the 11th International Conference on Urban Drainage, Edinburgh, Scotland, UK, 2008.

Bonta, J. V. and Rao, R.: Factors affecting the identification of independent storm events, J. Hydrol., 98(3-4), 275-293, 1988.

Calabro, P. S.: Design storms and water quality control, J. Hydrol. Eng.-ASCE, 9(1), 28-34, 2004.

Calabro, P. S. and Viviani, G.: Simulation of the operation of detention tanks, Water Res., 40, 83-90, 2006.

Deutsch, J.-C., Revitt, M., Ellis, B., and Scholes, L.: Report 5.1. Review of the use of stormwater BMPs in Europe, ADSS for the integration of stormwater source control into sustainable urban management strategies, Project under EU RTD 5th Framework Programme, DayWater Research Project, Middlesex University, 2003.

Di Toro, D. M. and Small, M. J.: Stormwater interception and storage, J. Env. Eng. Div.-ASCE, 105(EE1), 43-54, 1979.

Duan, Q., Sorooshian, S., and Gupta, V. K.: Effective and efficient global optimization for conceptual rainfall-runoff models, Water Resour. Res., 24(7), 1163-1173, 1992.

Ellis, J. B.: The management and control of urban runoff quality, J. Inst. Water Environ. Manage., 3, 116-124, 1989.

Engelhard, C., De Toffol, S., and Rauch, W.: Suitability of CSO performance indicators for compliance with ambient water quality targets, Urban Water J., 5(1), 43-49, 2008.

Francés, F. and Benito, J.: La modelación distribuida con pocos parámetros de las crecidas, Revista Ingeniería del Agua, 2(4), 7-24, 1995.

Francés, F., Vélez, J. J., Vélez, J. I., and Puricelli, M.: Distributed modelling of large basins for a real time flood forecasting system in Spain, Proceedings Second Federal Interagency Hydrologic Modelling Conference, Las Vegas, USA, July, CD Forma, Gan, TY and Biftu, GF, 3513-3524, 2002.

Francés, F., Vélez, J. I., and Vélez, J. J.: Split-parameter structure for the automatic calibration of distributed hydrological models, J. Hydrol., 332, 226-240, 2007.

Freni, G., Mannina, G., and Viviani, G.: Identifiability analysis for receiving water body quality modelling, Environ. Model. Softw., 24(1), 54-62, 2009.

Freni, G., Mannina, G., and Viviani, G.: Urban stormwater quality management: centralized versus source control, J. Water Res. Pl.-ASCE, 136(2), 268-278, 2010a.

Freni, G., Mannina, G., and Viviani, G.: Emission standards versus inmission standards for assessing the impact of urban drainage on ephemeral receiving water bodies, Water Sci. Technol., 61(6), 1617-1629, 2010b.

Freni, G., Mannina, G., and Viviani, G.: The influence of rainfall time resolution for urban water quality modelling, Water Sci. Technol., 61(9), 2381-2390, 2010c.

Hvitved-Jacobsen, T., Keinding, T., and Yousef, Y. A.: Urban runoff pollution removal in wet detention ponds, 4th International Conference on Urban Storm Drainage, 905-910, 1987. 
Lau, J., Butler, D., and Schütze, M.: Is combined sewer overflow spill frequency/volume a good indicator of receiving water quality impact?, Urban Water, 4, 181-189, 2002.

Ministerio de Medio Ambiente (MMA): Experiencia piloto de medición y estudio de las descargas de sistemas unitarios del alcantarillado a los medios receptores en tiempo de tormenta, en varias ciudades españolas (PROMEDSU), Secretaría de Estado de Agua y Costas, Dirección General de Obras Hidráulicas y Calidad de Aguas, Madrid, 2002.

Nash, J. E. and Sutcliffe, J. V.: River flow forecasting through conceptual models I. A discussion of principles, J. Hydrol., 10, 282290, 1970.

Rauch, W., Bertrand-Krajewsky, J. L., Krebs, P., Mark, O., Schilling, W., Schütze, M., and Vanrolleghem, P. A.: Deterministic modelling of integrated urban drainage systems, Water Sci. Technol., 45(3), 81-94, 2002.
Restrepo-Posada, P. J. and Eagleson, P. S.: Identification of independent rainstorms, J. Hydrol., 55(1-4), 303-319, 1982.

Saxton, K. E.: Soil water hydrology and chemical budgets with the enhanced SPAW model, Proceedings of the Federal Interagency Workshop Hydrologic Modeling Demands for the 90's, 6-9 June 1993, Ft. Collins, CO, 9 pp., 1993.

Temprano, J. and Tejero, I.: Detention storage volume for combined sewer overflow into a river, Environmental Technology, Selper Ltd., 23, 663-675, 2002.

Vélez, J. I.: Development of a conceptual hydrologic model for the simulation of river rising events, Ph.D. dissertation, Polytechnic University of Valencia, Department of Hydraulic Engineering and Environment, 266 pp., 2001.

Vélez, J. J., Puricelli, M., López Unzu, F., and Francés, F.: Parameter extrapolation to ungauged basins with a hydrological distributed model in a regional framework, Hydrol. Earth Syst. Sci., 13, 229-246, doi:10.5194/hess-13-229-2009, 2009. 